\title{
Assessment of complications after anesthesia in the postanesthetic care unit of the oncology hospital
}

\section{Onkoloji hastanesi postanestezik bakım ünitesinde anestezi sonrası komplikasyonların değerlendirilmesi}

\author{
Selma Ölmez ${ }^{1}$, Menşure Kaya² ${ }^{2}$ Dilek Kalayc ${ }^{2}$, Seda Yılmaz², Erdal Eskiçırak², Süheyla Ünver ${ }^{2}$ \\ ${ }^{1}$ Dışkapı Yıldırım Beyazıt Eğitim ve Araştırma Hastanesi Anesteziyoloji ve Reanimasyon Kliniği, Ankara, Türkiye \\ ${ }^{2}$ Dr AY Ankara Onkoloji Eğitim ve Araştırma Hastanesi Anesteziyoloji ve Reanimasyon Kliniği, Ankara, Türkiye
}

\section{ÖZET}

GÍRIŞ ve AMAÇ: Postoperatif komplikasyonlarla hızlı ve etkin mücadele etmek için cerrahi girişime özgü olan ve olmayan komplikasyonların bilinmesi ve bunlara yönelik önlemlerin alınması gerekir. Bu çalışmada amacımız postanestezik bakım ünitesinde (PABÜ) en sık karşılaşılan postoperatif komplikasyonları ve prediktif faktörleri belirlemekti.

YÖNTEM ve GEREÇLER: Elektif şartlarda operasyona alınan, 18-70 yaş arası 1000 hasta çalışmaya alındı. Hastalar ilk 24 saat boyunca kardiyovasküler, solunum, nöromüsküler, gastrointestinal, nörolojik ve diğer komplikasyonlar için izlendi. Hastaların yaş, cinsiyet, ASA skorları, preoperatif risk faktörleri, operasyon süresi, anestezi yöntemleri, postoperatif ağrı skorları ve postanestezik bakım ünitesinde kalış süreleri kayıt edildi. BULGULAR: Postoperatif en s1k kardiyovasküler sisteme ait komplikasyonlar (\%24) ve gastrointestinal sistem komplikasyonları (\%14) gözlendi. Kombine spinal epidural anestezi uygulanan hastalarda hipotansiyon ve taşikardi sıklığı ve spinal anestezi sonrası bradikardi görülme sıklığı daha yüksek bulundu. $(p<0,05)$. Preoperatif hipertansiyon mevcut olan hastalarda postoperatif hipertansiyon gelişme insidansının 3,6 kat daha fazla olduğu görüldü $(\mathrm{p}=0,001)$. Bulantı, genel anestezi alan hastalarda yüksek orandaydı $(\% 19,8)$. Uzun operasyon süresinin postoperatif bradikardi, taşikardi ve aritmi insidansını etkilediği saptandı $(\mathrm{p}<0,05)$. Yüksek ASA skoru ile kardiyovasküler ve solunum sistemi komplikasyonları arasında pozitif korelasyon mevcuttu. Yaş, ASA skoru, preoperatif sistemik hastalık varlığı ve operasyon süresinin PABÜ'de kalma süresi etkileyen faktörler olduğu saptandi.

TARTIŞMA ve SONUÇ: Çalışmamızda, en sık karşılaşılan postoperatif komplikasyonun kardiyovasküler sistem ait komplikasyonlar olduğu saptandı. Ağrı ve bulantı-kusma insidansının literatüre benzer şekilde yüksek oranda olduğu görüldü. Kardiyovasküler ve solunum komplikasyonlarının PABÜ'de kalma süresini uzattı̆̆ saptandı. Yaş, eşlik eden komorbiditelerin varlığı ve ASA skorlaması olası komplikasyonların belirleyicileri olarak bulundu. Bu risk faktörlerinin varlığ hem anestezi hem cerrahi ekip için uyarıcı olmalıdır.

Anahtar Kelimeler: Anestezi, postoperatif, komplikasyonlar, postanestezik bakım ünitesi

\section{ABSTRACT}

INTRODUCTION: In order to fight postoperative complications quickly and effectively, it is necessary to know the complications that are specific or not specific to the surgical procedure and to take precautions against them. Our aim in this study was to determine the most common postoperative complications and predictive factors in the postanesthetic care unit (PACU).

METHODS: A total of 1000 patients between 18-70 years of age undergoing elective surgery were included in the study. Patients were monitored for cardiovascular, respiratory, neuromuscular, gastrointestinal, neurologic and other complications during the first 24 hours of the operation. Patients' age, gender, ASA scores, preoperative risk factors, duration of operation, anesthesia methods, postoperative pain scores and duration of stay in the postanesthetic care unit were recorded.

RESULTS: Postoperative cardiovascular complications (24\%) and gastrointestinal system complications (14\%) were observed most frequently. The incidence of hypotension and tachycardia in patients undergoing combined 
spinal epidural anaesthesia and the incidence of bradycardia after spinal anesthesia was higher $(\mathrm{p}<0,05)$. The incidence of postoperative hypertension development was 3,6 times higher in patients with preoperative hypertension $(\mathrm{p}=0.001)$. Nausea was higher in patients receiving general anesthesia $(19,8 \%)$. It was found that the long operation time effected postoperative bradycardia, tachycardia and arrhythmia incidence $(\mathrm{p}<0,05)$. There was a positive correlation between high ASA scores and cardiovascular and respiratory complications. DISCUSSION AND CONCLUSION: In our study, the most common postoperative complications were cardiovascular system complications. It was seen that the incidence of pain and nausea-vomiting was similarly high in the literature. It was found that the cardiovascular and respiratory complications extended the duration of stay in PACU. Age, presence of accompanying comorbidities, and ASA scoring were found to be determinants of possible complications. The presence of these risk factors should be stimulating for both the anesthesia and the surgical team.

Keywords: Anaesthesia, postoperative, complications, Post-anaesthesia Care Unit

\section{GíRIŞ}

Postoperatif gelişebilecek komplikasyonlar yapılan ameliyatın fonksiyonel sonuçlarını etkiler ve bu durum hastanın ameliyat öncesi mevcut fonksiyonel kapasitesinin bile kaybolmasına hatta hastanın ölümüne neden olabilir. PABÜ 'de meydana gelen kritik olaylar genellikle kardiyovasküler ve solunum sistemi ile ilişkilidir.

Operasyon öncesi dönemde hastanın fizyolojik durumunun iyi değerlendirilmesi, gelişebilecek komplikasyonların bilinmesi ve erken tanınması hastanın yaşam boyu sakatlık ve/veya ölüm riskini büyük ölçüde azaltmaya olanak sağlar. Ayrıca komplikasyonları veya semptomları tanımak ve komplikasyonları önceden tahmin ederek risk azaltma önlemlerine odaklanmak postoperatif bakım ünitesinin kalitesini arttırır.

$\mathrm{Bu}$ çalışmada amacımız; hastanemiz postanestezik bakım ünitesinde (PABÜ) sik karşılaşılan postoperatif komplikasyonları saptamak ve gelişen komplikasyonlar için prediktif faktörleri tanımlamaktır.

\section{Materyal ve Metod}

Çalışmamız Ankara Numune Eğitim ve Araştırma Hastanesi Klinik Araştırmalar Etik Kurul onay1 (14/2013) ve bilgilendirilmiş gönüllü olur alınması sonrası Dr. AY Onkoloji Eğitim ve Araştırma Hastanesi'nde yapıldı. Elektif şartlarda genel anestezi veya rejyonal anestezi uygulanarak operasyona alınan ve anestezi sonrası bakım ünitesinde takip edilen, 18-70 yaş arasındaki 1000 hasta çalışmaya alındı. Çalışma prospektif gözlemsel bir çalışmadır. Hastalar, preoperatif anestezi viziti sırasında çalışma hakkında bilgilendirilerek onamları alındı. Acil şartlarda operasyona alınan hastalar çalışmaya dâhil edilmedi.

Hastaların yaş, cinsiyet, ASA skorları, preoperatif risk faktörleri ve operasyon nedenleri not edildi. Premedikasyon, anestezi yöntemi, operasyon süresi, hasta pozisyonu, intraoperatif ve postoperatif transfüzyon gereksinimleri, invaziv girişimler, planlanan postoperatif analjezi yöntemleri kaydedildi. Postoperatif ağrı, Visüel Ağrı Skalası (VAS) kullanılarak PABÜ'ne kabullerinde ve çıkışlarında olmak üzere iki kez değerlendirildi (0:ağr1 yok, 10:dayanılmaz ağr1). Ayrıca hastaların postanestezik bakım ünitesinde kalış süreleri not edildi.

Postanestezik bakım ünitesinde takibe alınan hastalar, gelişen kardiyovasküler, respiratuar, gastrointestinal ve nörolojik komplikasyonla raçısından takip edildi. Sik karşılaşılan komplikasyonlar aşağıdaki siniflama ile tanımlandi;

1. Kardiyovasküler sisteme ait komplikasyonlar

a. Kan basıncı değişiklikleri:

b. Kalp hızı değişiklikleri

c. Ritm bozuklukları

d. Miyokardial iskemi

e. Kardiyak Arrest 
2. Respiratuar sisteme ait komplikasyonlar
a. Desatürasyon
b. Hipoksemi
c. Hava yolu obstrüksiyonu
d. Pnömotoraks
e. Hiperkapni
f. Aspirasyon
g. Pulmoner Emboli

3. Nörolojik sisteme ait komplikasyonlar
a. Deliryum
b. Ajitasyon
c. İnme
d. Sinir hasarı

4. Gastrointestinal sisteme ait komplikasyonlar
a. Bulant1 ve kusma
b. İleus
c. Aspirasyon

5. Diğer komplikasyonlar
a. Hipertermi
b. Hipotermi
c. Titreme
d. Alerjik reaksiyonlar
e. Rekürarizasyon

\section{İstatistiksel Analiz}

İstatistiksel değerlendirme SPSS 16.00 paket programında yapıldı. Anestezi yöntemleri; genel anestezi (GA), spinal anestezi (SA), kombine spinal-epidural anestezi (KSEA) ve laringeal maske anestezisi (LMA) uygulamas1 alt gruplarına ayrilarak hastaların verileri karşılaştırıldı.

İstatistiksel analiz verileri [ortalama \pm standart sapma, ortanca (\%25-75), (MinMaks), n (\%)] olarak sunuldu. Yapılan tüm istatistiksel analizlerde $p<0,05$ değeri anlamlı kabul edildi.

$\begin{array}{crr}\text { Ölçülebilen } & \text { parametrelere } \\ \text { Kolmogorov-Smirnov testi } & \text { uygulanarak }\end{array}$ dağılımın normal olup olmadığı belirlendi. Gruplar arasında fark olup olmadığını belirlemede bağımsızgruplarda Kruskal-Wallis testi ile değerlendirildi, farklılık olması durumunda Mann-Whitney $U$ testi ile karşılaştırılma yapıldı.

Nitel verilerin değerlendirmesi Chisquare veya Fisher'in kesin Chi-quare testleri ile yapıldı.

Postoperatif bakımda kalma süresi ile veriler arasındaki ilişki ise Pearson veya Spearman korelasyon analizi ile değerlendirildi.0-0.49 arasında ise korelasyon zayıf, 0.5-0.74 arasında ise orta derecede, 0.751 arasında ise kuvvetli ilişki var olarak değerlendirildi.

\section{Bulgular}

En s1k operasyon nedeni \% 10,8 ile meme karsinomu olup, 356 hastanın malignite tanıs 1 ile operasyona alındığı tesbit edildi (Tablo 1). Preoperatif risk faktörlerinden sıklığı en fazla olan sigara kullanımı $(\% 28,1)$, hipertansiyon $(\% 20,6)$ ve diabetes mellitus $(\% 10,1)$ idi (Tablo 2). İntraoperatif işlemler ve anestezi uygulamaları Tablo 3 te, operasyon süresi, transfüzyon ihtiyacı, РАBÜ'de kalma süreleri, derlenme ve ağrı skorları Tablo 4 te verildi. Operasyona alınan hastaların \%76's1 ASA II risk grubunda hastalardı. (Tablo 5)

Hastaların \%49,1'inde komplikasyon saptandı Kardiyovasküler sisteme ait komplikasyonlar $(\% 24,4)$ ve gastrointestinal sistem komplikasyonları (\%14,3 ) en s1k karşılaştığımız komplikasyonlar olarak tesbit edildi (Tablo 6,7). Hipertansiyon ve bradikardi en sık karşılaşılan postoperatif kardiyovasküler sisteme ait komplikasyonlard.

Anestezi yöntemine göre komplikasyonlar değerlendirildiğinde; spinal anestezi sonrası bradikardi, kombine spinal 
epidural anestezi sonras1 hipotansiyon ve taşikardi insidansı daha yüksekti (Tablo 8). Hastaların \%14,3'ünde bulant1, \%1,6'sında kusma gelişti. Bulantı insidansı istatistiksel olarak anlamlı olmamakla birlikte kadınlarda daha fazlaydı (kadınlarda \%19 ve erkeklerde \%13,9) $(\mathrm{p}=0,095)$. Preoperatif hipertansiyonu olan hastalarda postoperatif hipertansiyon gelişme insidansının 3,6 kat daha fazla olduğu $(p<0,001)$. uzun operasyon süresinin postoperatif taşikardi ve aritmi gelişimini $\operatorname{artırdı} \breve{g}_{1} \operatorname{saptand} 1(p=0,001$ ve $p=0,005)$.

İleri yaş ve yükssek ASA skorlarının PABÜ'de kalma süresini uzattı̆ğ, ayrıca preoperatif diabetes mellitus (DM), hipertansiyon (HT), kronik obstrüktif akciğer hastalı̆̆1 (KOAH) ve aterosklerotik kalp hastalığı (ASKH) varlığının PABÜ'de kalma süresini etkilediği görüldü. PABÜ'de kalma süresini ekileyen en önemli faktör olarak operasyon süresi saptandı. (Tablo 9)

Malignite tanis1 olan hastalarda özellikle solunum sistemi komplikasyonlarının (hipoksemi, hiperkapni, hipoventilasyon) malign olmayan hastalara göre daha fazla olduğu saptandı. (Tablo 10)

\section{Tartışma}

Postoperatif komplikasyonlar hem hasta morbidite ve mortalitesini artırmakta hem de kalite iyileştirme programları için ana hedeflerden biri olamaya devam etmektedir(1). Anestezi sonrası gelişen komplikasyonların sıklığını doğru olarak değerlendirmek zordur (2). Çalışmamızda PABÜ'de komplikasyon oran $\% 49$ gibi yüksek bir oranda tesbit edildi. Postoperatif erken dönemde komplikasyonların gelişimi; kullanılan anestezinin tipi, ameliyat nedeni olan hastalık, ameliyat tekniği, hastanın yaşı ve sistemik hastalıkların varlığı gibi faktörler ile değişiklik göstermektedir (1-4). Anestezi sonrası bakım ünitesinde komplikasyon görülme insidansları farklı çalışmalarda farklı oranlarda verilmiştir. Hines ve arkadaşları yaptıkları çalışmada, anestezi sonrası bakım sırasında genel komplikasyon s1klı̆̆ının \%23.7 gibi neredeyse her 5 hastadan birinde komplikasyon görüldüğünü bildirmişlerdir.(5) Cooper ve arkadaşları (6) bu oranı $\% 18$, Bruins ve ark. ise \% 74 olarak bildirmişlerdir (7). Farklı insidanslar, farklı raporlama tekniklerini, hasta popülasyonlarındaki farklılıkları veya her ikisini de yansitıyor olabilir.

Komplikasyonların ortaya çıkma olasılığı üzerine yapılmış çalışmalar, sistemlere göre dağılım hakkında farklı sonuçlar bildirmektedir $(8,9)$. Çalışmamızda komplikasyonları sistemlerine göre incelediğimizde birinci ana grubu kardiyovasküler sistem komplikasyonları $(\% 24,4)$ oluşturmakta. Zelker ve Wells bir aylık dönemde derlenme odasında görülen komplikasyonların insidansını \%30 olarak bulmuşlar ve 443 hastanın 68'inde (\%15.3) kardiyovasküler komplikasyon bildirmişlerdir (1). Bu komplikasyonlardan disritmi (\%14), hipertansiyon (\%1) ve hipotansiyon en s1k görülenleridir. Bizim çalışmamızda da kardiyovasküler komplikasyon oranı \%24,4 olup en s1k hipertansiyon (\% 13,9), disritmi $(\% 7,2)$ ve hipotansiyon(\%3,2) gözlendi. Özellikle hipertansiyonda belirgin bir yüksek oran tespit edildi. Çalışmamızda \%20 oranında yandaş hastalığı hipertansiyon olan hastaların varlığı bu yüksekliğin sebeplerinden biri olabilir. Kombine spinal epidural anestezi uygulanmış hastalarda hem kardiyovasküler hemde solunumsal komplikasyonların daha fazla görülmesinin nedeni bu hastaların büyük çoğunluğunun bilateral diz artroplastisi ve diğer majör ortopedik onkolojik vakalar olması olabilir. Bu operasyonlarda intraoperatif ve postoperatif kan kaybi transfüzyon gereksiniminin daha yüksek olmasına da neden olmuştur.

Yaş arttıkça yandaş hastalıklar ile majör ve destekleyici sistemlerin yetersizliği nedeniyle mortalite ve morbidite yükselmektedir(10). Artan yaşla birlikte 
otonom sinir sistemi ve kardiyovasküler sistem hemodinamik stabiliteyi korumakta zorlanır ve bazı organlarda fonksiyonel rezerv değişiklikleri meydana gelir $(10,11)$. Çalışmamızda da literatür ile uyumlu olarak yaş ile birlikte postoperatif komplikasyon insidansında artış olduğu ve PABÜ süresinin uzadığı görüldü.

Çalışmada hastalarımızın yaklaşı $1 \mathrm{k} \%$ 89'u ASA I ve II hasta olmasına rağmen yüksek oranda komplikasyon insidans1 tesbit ettik. ASA III ve IV hastaları için iyi bir peroperatif hazırlık yapılmasinın daha az komplikasyonla karşılaşılmasına neden olduğunu düşünmekteyiz.

Operasyon süresi ile ilgili olarak süre uzadıkça postoperatif komplikasyon riskinin arttığ1 kabul edilir (11). Operasyon süresi uzadıkça cerrahiye ait ağrı, volüm kaybı ve cerrahi strese yanıt artmakta, bu durum vital organların perfüzyonunu sağlamaya yönelik dolaşımdaki katekolaminleri arttırmasının yanı sıra miyokardın oksijen tüketimini de arttırmaktadır. Sonuçta kardiyak instabilitesi olan hastada iskemi, yetmezlik ve aritmilere neden olmaktadır. Operasyon süresi ile ilgili artan volüm kayıpları da hemodinamik stabiliteyi değiştirmektedir (11). Diğer çalışmalara benzer şekilde çalışmamızda da operasyon süresinin uzamasının taşikardi ve aritmi insidansını artırdığı, ayrıca PABÜ'nde kalma süresini etkileyen en önemli faktör olduğu saptand 1

Bulant1 ve kusma insidans1, anestezi sonras1 yoğun bakımda \%5-60 gibi geniş bir yelpazede görülmektedir $(12,13)$. Bu farklılık özellikle yapılan cerrahi prosedüre bağlı değişmektedir. Bizim çalışmamızda da bu oranlar sirasiyla $\% 14,3$ ve $\% 1,6$ olarak bulunmuştur. Bazı çalışmalar insidansın kadınlarda daha sık olduğunu, ancak istatistiksel olarak anlamlı bulunmadığını bildirmektedir $\quad(13,14)$. Çalışmamızda kadınlarda daha fazla oranda bulantı (kadınlarda \%19 ve erkeklerde \%13,9) gözlemlememize rağmen bu faklılık anlamlı değildi. Uzun süren operasyonlardan sonra bu sıklığın artışından yola çıkarak postoperatif bulantı-kusmanın operasyon süresinden etkilenebileceğini, bunun sebebinin hastaların emetojenik ilaçlara fazlaca maruz kalmasının olabileceği belirtilmiştir $(12,13,14)$. Bizde operasyon süresinin uzamasının bulantı insidansını artırdığını gözlemledik.

Genel anestezi sonras1 ajitasyon anlamlı olarak yüksek bulunurken hastaların hiçbirinde deliryum gözlenmedi. Bunun nedeni deliryum tanısı için postoperatif herhangi bir tarama metodunun kullanılmamasiydi. $\mathrm{Bu}$ da çalışmamızın eksiklikliğiydi.

Kardiyovasküler komplikasyon insidansı genel popülasyonla benzer oranlarda iken (malignite tanıs1 olanlarda \%24, olmayanlarda \%24,7) solunum sistemi komplikasyonlarının kanser tanısı ile opere edilen hastalarda daha fazla olduğunu saptadı (stras1 ile \%12,9- \%2,4). Bulant1-kusma insidansı da malign hastalarda daha yüksek idi. (\%26,1-\% 10,2). Cerrahi öncesinde veya sırasındaki malignitenin yaygınlığı, medikal tedavi uygulamaları ve bunların komplikasyonları, eşlik eden organ ve sistem yetmezlikleri, yapılan cerrahinin büyüklügü ya da cerrahi komplikasyonlar gibi nedenler hastalarin postoperatif dönemde daha fazla komplikasyona açık hale gelmesine neden olmaktadır. Hasta grubumuzun içinde kanser cerrahisi yapılan hastaların varlı̆gı, genel komplikasyon oranımızın da literatürdeki oranlara göre daha yüksek olmasına neden olmuş olabilir.

Literatürde, cerrahi geçiren hastaların yaklaş1k dörtte üçünde ağr1 geliştiği ve bunların \%80'inde ağrının orta ve yüksek şiddette olduğu bildirilmişti $(15,16,17)$. Postoperatif ağriya bağlı segmental ve suprasegmental reflekslerin uyarılması sempatik nöronları stimüle ederek taşikardiye, 
strok volümde ve kardiyak outputta azalmaya yol açar. Dolayısı ile kalbin iş yükünde ve miyokardial oksijen tüketiminde artışa neden olur. $\mathrm{Bu}$ durum özellikle koroner iskemisi olanlarda soruna neden olur. Başarılı bir postoperatif analjezi, solunum fonksiyonlarında düzelme, kardiyak yükün azalması, tromboembolik komplikasyon insidansının düşmesi, nöroendokrin ve sempatik sinir sisteminde stres yanıtın azalması gibi etkileri ile morbidite ve mortalitenin azalmasını sağlayabilmektedir (18). Çalışmamızda özellikle genel anestezi yapılan hastalarda VAS değerlerinin daha yüksek olduğu, nöroaksiyal blok yapılan hastalarda ise PABÜ' ne ilk çıkışta analjezik ihtiyacının daha az olduğunu gördük. Postoperatif ağrının tedavisinde en sik tercih edilen ajanlar opioidlerdir. Biz, çalışmamızda postoperatif analjezi için en fazla $(\% 45,6)$ Tramadol HCL + Non steroid anti-inflamatuar ilaç kombinasyonunun tercih edildiğini hasta kontrollü analjezi (HKA) yönteminin ise yeterli oranda kullanılmadığını gözlemledik. Özellikle genel anestezi yapılan hastalarda \%55 gibi yüksek oranda ağrı görülmesi ve VAS değerlerinin daha yüksek olması postoperatif analjezi amacıyla daha güçlü opioidlerin tercih edilmemesinden kaynaklanıyor gibi görünmektedir. HKA'nin düşük kullanım oranı hastanemizdeki postoperatif analjezi için bu yöntemin kullanım insidansını objektif olarak yansitmamakta, çünkü dönemsel olarak cihaz eksikliği ve HKA setlerinin olmayışı bu oranın düşmesine sebep olmaktadır. Ayrıca uygun hastalarda postoperatif analjezi için rejyonal analjezi yöntemlerinin mutlaka düşünülmesi gerektiği kanaatindeyiz.

Çalışmamız; yaş, eşlik eden hipertansiyon ve aterosklerotik kalp hastalı̆ 1 varlığ1, yüksek ASA skorunun oluşabilecek komplikasyonların temelinde belirleyici faktörler olduğunu göstermiştir. Anestezi pratiğindeki gelişmelere ve monitorizasyondaki ilerlemelere rağmen, halen ani post anestezi komplikasyonları ortaya çıkmaktadır. PABÜ' deki kritik olaylara ilişkin veriler, bu tür olayları öngörmek ve önlemek ve bakım süreçlerini geliştirmek için kullanılabilecek önrmli bir bilgi kaynağıdır. Anestezi sonrası bakım ünitelerinde yapılan hızlı ve etkin müdahalelerle birçok komplikasyon ya da fizyolojik dekompansasyon, sistemik hasar oluşmasına firsat verilmeden çözümlenebilmektedir. Böylece gerçekten yoğun bakım ihtiyacı olan hastaların önceden belirlenebilmesi ve sınırlı sayıdaki yoğun bakım yataklarının organizasyonu ve verimli kullanılabilmesi de sağlanabilir.

Çıkar Çatışması: Yok 
Tablo 1. Hastaların tanıları, hasta sayısı (n)

\begin{tabular}{|c|c|}
\hline Hastalık adı & Hasta Sayısı \\
\hline Malignite & 356 \\
\hline Meme karsinomu & 108 \\
\hline Gastointestinal sistem tümörleri & 77 \\
\hline Genitoüriner sistem tümörleri & 84 \\
\hline Kemik tümörü & 49 \\
\hline Troid tümörleri & 24 \\
\hline Baş-boyun tümörleri & 14 \\
\hline Ortopedi & 206 \\
\hline Genel Cerrahi & 164 \\
\hline KBB & 48 \\
\hline Üroloji & 74 \\
\hline Kadın Doğum & 53 \\
\hline Beyin Cerrahi & 15 \\
\hline Plastik Cerrahi & 25 \\
\hline Kalp Damar Cerrahi & 16 \\
\hline
\end{tabular}


Tablo 2. Hastaların demografik özellikleri, komorbiditeler, hasta sayısı: n(\%)

\begin{tabular}{|c|c|c|c|c|}
\hline & $\begin{array}{l}\text { Genel Anestezi } \\
\qquad(n=652)\end{array}$ & $\begin{array}{c}\text { Spinal } \\
\text { Anestezi } \\
(\mathbf{n}=\mathbf{2 1 2})\end{array}$ & $\begin{array}{l}\text { Kombine Spinal- } \\
\text { Epidural Anestezi } \\
\qquad(\mathrm{n}=78)\end{array}$ & $\begin{array}{l}\text { LMA } \\
(n=58)\end{array}$ \\
\hline Yaş (yıl) & $\begin{array}{c}48,38 \pm 13,15 \\
(18-70)\end{array}$ & $\begin{array}{c}47,27 \pm 15,85 \\
(18-70)\end{array}$ & $\begin{array}{c}55,79 \pm 12,54 \\
(20-70)\end{array}$ & $\begin{array}{c}49,00 \pm 16,13 \\
(18-70)\end{array}$ \\
\hline Sigara & $174(\% 26,7)$ & $84(\% 39,6)$ & $9(\% 11,5)$ & $14(\% 24,1)$ \\
\hline Alkol & $15(\% 2,3)$ & $14(\% 6,6)$ & $1(\% 1,3)$ & $1(\% 1,7)$ \\
\hline DM & $59(\% 9)$ & $18(\% 8,5)$ & $15(\% 19,2)$ & $9(\% 15,5)$ \\
\hline HT & $123(\% 18,9)$ & $38(\% 17,9)$ & $34(\% 43,6)$ & $11(\% 19)$ \\
\hline КОАН & $36(\% 5,5)$ & $17(\% 8)$ & $5(\% 6,4)$ & $0(0)$ \\
\hline ASKH & $38(\% 5,8)$ & $19(\% 8,5)$ & $13(\% 16,7)$ & $2(\% 3,4)$ \\
\hline KBY & $1(\% 0,2)$ & $0(0)$ & $0(0)$ & $0(0)$ \\
\hline DVT & $12(\% 1,8)$ & $5(\% 2,4)$ & $4(\% 5,1)$ & $3(\% 5,2)$ \\
\hline
\end{tabular}

Ort \pm SS (Min-Maks), (DM: DiabetesMellitus, HT: Hipertansiyon, KOAH: kronik obstrüktif akciğer hastalığı, ASKH: aterosklerotik kalp hastalığı, KBY: kronik böbrek yetmezliği, DVT: derin ven trombozu, LMA: laringeal maske 
Tablo 3. İntraoperatif yapılan işlemler ve anestezi uygulamaları, hasta sayısı: n (\%)

\begin{tabular}{||l|c||}
\hline & $\begin{array}{c}\text { Grup } \\
(\mathbf{n}=\mathbf{1 0 0 0})\end{array}$ \\
\hline \hline Premedikasyon & $970(\% 97)$ \\
\hline Anestezi & $652(\% 65,2)$ \\
Genel & $58(\% 5,8)$ \\
LMA & $78(\% 7,8)$ \\
Kombine spinal/epidural & $212(\% 21,2)$ \\
Spinal & $710(\% 71)$ \\
\hline Genel anestezi & $290(\% 29)$ \\
Rejyonel anestezi & $70(\% 7)$ \\
\hline Hasta pozisyonu & $46(\% 4,6)$ \\
Litotomi & $11(\% 1,1)$ \\
Pron & $7(\% 0,7)$ \\
Sağ lateral & $866(\% 86,6)$ \\
Sol Lateral & $94(\% 9,4)$ \\
\hline Supin & $231(\% 23,1)$ \\
\hline Nazogastrik sonda & $636(\% 63,6)$ \\
\hline Isi takibi & $638(\% 63,8)$ \\
\hline Antikolinerjik & $76(\% 7,6)$ \\
\hline Antiemetik & $47(\% 4,7)$ \\
\hline Arter kanülasyonu & \\
\hline Santral kanülasyon & \\
\hline
\end{tabular}

Tablo 4. Anestezi yöntemlerine göre operasyon süresi transfüzyon ihtiyac1, PABÜ’de kalma süreleri [Ort \pm SS (Min-Maks), hasta sayıs1: n(\%)]

\begin{tabular}{||l|c|c|c|c|c||}
\hline & $\begin{array}{c}\text { Genel } \\
\text { Anestezi } \\
(\mathbf{n = 6 5 2})\end{array}$ & $\begin{array}{c}\text { Spinal } \\
\text { Anestezi } \\
(\mathbf{n = 2 1 2})\end{array}$ & $\begin{array}{c}\text { Kombine Spinal- } \\
\text { Epidural Anestezi } \\
(\mathbf{n = 7 8})\end{array}$ & $\begin{array}{c}\text { LMA } \\
(\mathbf{n = 5 8})\end{array}$ & $\mathbf{P}^{*}$ \\
\hline $\begin{array}{l}\text { Operasyon } \\
\text { süresi (dk) }\end{array}$ & $\begin{array}{c}103,8 \pm 67,7^{*} \\
(10-480)\end{array}$ & $\begin{array}{c}44,0 \pm 23,0 \\
(10-120)\end{array}$ & $\begin{array}{c}100,8 \pm 27,5^{*} \\
(60-180)\end{array}$ & $\begin{array}{c}27,9 \pm 15,1 \\
(5-70)\end{array}$ & $<0.0001$ \\
\hline $\begin{array}{l}\text { PABÜ'de kalma } \\
\text { süresi (dk) }\end{array}$ & $\begin{array}{c}247,1 \pm 408,2^{*} \\
(35-2460)\end{array}$ & $\begin{array}{c}92,8 \pm 101,3 \\
(30-1200)\end{array}$ & $\begin{array}{c}188,4 \pm 240,9 * \\
(60-1260)\end{array}$ & $\begin{array}{c}65,3 \pm 13,7 \\
(45-120)\end{array}$ & $<0.0001$ \\
\hline $\begin{array}{l}\text { İntraoperatif } \\
\text { transfüzyon } \\
\text { ihtiyacı (n(\%)) }\end{array}$ & $33(5,1)$ & $3(1,4)$ & $20(25,6)^{*}$ & $0(0)$ & $\begin{array}{c}\mathrm{X}^{2}=41.433 \\
<0.0001\end{array}$ \\
\hline $\begin{array}{l}\text { Postoperatif } \\
\text { transfüzyon } \\
\text { (n(\%)) }\end{array}$ & $18(2,8)$ & $8(3,8)$ & $51(65,4)^{*}$ & $0(0)$ & $\begin{array}{c}\mathrm{X}^{2}=396.57 \\
4\end{array}$ \\
\hline VAS 1 & $2,1 \pm 2,2$ & $0,1 \pm 0,8$ & $0,6 \pm 1,7$ & $1,5 \pm 2,1$ & $<0.0001$ \\
\hline VAS çıış & $(0-8)$ & $(0-6)$ & $(0-7)$ & $0.8)$ & $<0.0001$ \\
\hline \hline
\end{tabular}

${ }^{*} \mathbf{p}<0,05$ anestezi yöntemleri karşılaştırıldığında, LMA: laringeal maske, PABÜ: postanestezik bakım ünitesi, VAS: visüel ağrı skoru, VAS1 PABÜ'ne kabüllerindeki VAS, VAS çılaş: PABÜ'den servise gönderildiklerindeki VAS 
Tablo 5. ASA sinıflaması

\begin{tabular}{|l|l|l|}
\hline ASA & Hasta sayısI (n) & $\%$ \\
\hline I & 129 & $\% 12,9$ \\
\hline II & 763 & $\% 76,3$ \\
\hline III & 105 & $\% 10,5$ \\
\hline IV & 3 & $\% 0,3$ \\
\hline N & 1000 & \\
\hline
\end{tabular}

Tablo 6. Postoperatif kardiyovasküler ve respiratuar komplikasyonlar hasta sayısı: n $(\%)$

\begin{tabular}{|c|c|}
\hline & $\begin{array}{l}\text { Grup } \\
\qquad(n=1000)\end{array}$ \\
\hline Hipertansiyon & $139(13,9)$ \\
\hline Bradikardi & $46(4,6)$ \\
\hline Hipotansiyon & $32(3,2)$ \\
\hline Aritmi & $14(1,4)$ \\
\hline Taşikardi & $12(1,2)$ \\
\hline Arrest & $1(0,1)$ \\
\hline MI & $0(0)$ \\
\hline Desatürasyon & $33(3,3)$ \\
\hline Hipoksemi & $20(2)$ \\
\hline Hiperkapni & $9(0,9)$ \\
\hline Reentübasyon & $2(0,3)$ \\
\hline Hava yolu obstrüksiyonu & $0(0)$ \\
\hline Pnömotoraks & $0(0)$ \\
\hline Pulmoner Emboli & $0(0)$ \\
\hline Hava yolu obstrüksiyonu & $0(0)$ \\
\hline
\end{tabular}


Tablo 7. Postoperatif gastrointestinal sistem, nörolojik ve diğer komplikasyonlar, hasta sayısı: n (\%)

\begin{tabular}{||l|c||}
\hline \hline Bulantı & $\begin{array}{c}\text { Grup } \\
(\mathbf{n}=\mathbf{1 0 0 0})\end{array}$ \\
\hline Kusma & $143(14,3)$ \\
\hline Aspirasyon & $16(1,6)$ \\
\hline İleus & $0(0)$ \\
\hline \hline Ajitasyon & $0(0)$ \\
\hline Deliryum & $22(2,2)$ \\
\hline İnme & 0 \\
\hline Sinir hasarı & 0 \\
\hline \hline Titreme & 0 \\
\hline Alerji & $10(\% 1)$ \\
\hline Hipotermi & $3(\% 0,3)$ \\
\hline Derin ven trombozu & $7(\% 0,7)$ \\
\hline Ateş & $0(0)$ \\
\hline Ölüm & $0(0)$ \\
\hline \hline
\end{tabular}

Tablo 8. Anestezi yöntemlerine göre komplikasyon insidanslarının karşılaştırılması hasta sayısı: n(\%)

\begin{tabular}{|c|c|c|c|c|c|}
\hline & $\begin{array}{c}\text { Genel } \\
\text { anestezi } \\
(n=652)\end{array}$ & $\begin{array}{c}\text { Spinal } \\
\text { anestezi } \\
(n=212)\end{array}$ & $\begin{array}{l}\text { Kombine } \\
\text { spinal- } \\
\text { epidural } \\
\text { anestezi } \\
(n=78)\end{array}$ & $\begin{array}{c}\text { LMLA } \\
(n=58)\end{array}$ & $\mathbf{P}$ \\
\hline Bulantı & $129(19,8)^{*}$ & $7(3,3)$ & $4(5,1)$ & $3(5,2)$ & $\begin{array}{c}\mathrm{X}^{2}=55.437 \\
<0.0001\end{array}$ \\
\hline Kusma & $14(2,2)$ & $0(0)$ & $1(1,3)$ & $1(1,7)$ & $\begin{array}{c}\mathrm{X}^{2}=4.751 \\
0.191\end{array}$ \\
\hline Hipertansiyon & $97(14,9)$ & $19(9)$ & $13(16,7)$ & $10(17,5)$ & $\begin{array}{c}\mathrm{X}^{2}=5.984 \\
0.112\end{array}$ \\
\hline Hipotansiyon & $9(1,4)^{\#}$ & $11(5,2)$ & $12(15,4)^{\circ}$ & $O(0)$ & $\begin{array}{c}\mathrm{X}^{2}=34.809 \\
<0.0001\end{array}$ \\
\hline Aritmi & $9(1,4)$ & $4(1,9)$ & $1(1,3)$ & $O(0)$ & $\begin{array}{c}\mathrm{X}^{2}=1.194 \\
0.754\end{array}$ \\
\hline Bradikardi & $17(2,6)$ & $23(10,8)^{\circ \circ}$ & $6(7,7)$ & $O(0)$ & $\begin{array}{c}\mathrm{X}^{2}=27.658 \\
<0.0001\end{array}$ \\
\hline Taşikardi & $6(0,9)$ & $O(0)$ & $6(7,7)^{\circ}$ & $O(0)$ & $\begin{array}{c}\mathrm{X}^{2}=19.434 \\
<0.0001\end{array}$ \\
\hline Arrest & $1(0,2)$ & $O(0)$ & $O(0)$ & $O(0)$ & $\begin{array}{c}\mathrm{X}^{2}=0.534 \\
0.911\end{array}$ \\
\hline Reentübasyon & $2(0,3)$ & $O(0)$ & $O(0)$ & $0(0)$ & $\begin{array}{c}\mathrm{X}^{2}=1.070 \\
0.784\end{array}$ \\
\hline Desatürasyon & $29(4,4)$ & $O(0)^{0}$ & $3(3,8)$ & $1(1,7)$ & $\begin{array}{c}\mathrm{X}^{2}=10.451 \\
0.015\end{array}$ \\
\hline Hipoksemi & $16(2,5)$ & $o(0)$ & $3(3,8)$ & $1(1,7)$ & $\begin{array}{c}\mathrm{X}^{2}=6.391 \\
0.094\end{array}$ \\
\hline Hiperkapni & $9(1,4)$ & $O(0)$ & $O(0)$ & $O(0)$ & $\begin{array}{c}\mathrm{X}^{2}=4.847 \\
0.183\end{array}$ \\
\hline Alerji & $3(0,5)$ & $O(0)$ & $O(0)$ & $O(0)$ & $\begin{array}{c}\mathrm{X}^{2}=1.606 \\
0.658\end{array}$ \\
\hline Hipotermi & $6(0,9)$ & $1(0,5)$ & $0(0)$ & $O(0)$ & $\begin{array}{c}\mathrm{X}^{2}=1.559 \\
0.669\end{array}$ \\
\hline Ajitasyon & $20(3,1)^{*}$ & $1(0,5)$ & $O(0)$ & $1(1,7)$ & $\begin{array}{c}\mathrm{X} 2=9.883 \\
0.020\end{array}$ \\
\hline
\end{tabular}

Adress for correspondence: MenşureKaya, Dr AY Onkoloji Eğitim Araştırma Hastanesi Anestezi Kliniği Demetevler 06170 Ankara - Türkiye e-mail: mensurekava@vahoo.com

Available at www.actaoncologicaturcica.com

Copyright $\odot$ Ankara Onkoloji Hastanesi 
Tablo 9. PABÜ'nde kalma süresini etkileyen faktörler

\begin{tabular}{|c|c|c|c|}
\hline Parametre & Korelasyon & Parametre & Korelasyon \\
\hline Yaş & $\begin{array}{l}\mathrm{r}=0.220 \\
\mathrm{p}<0.0001\end{array}$ & Kanama & $\begin{array}{l}\mathrm{r}=0.173 \\
\mathrm{p}<0.0001\end{array}$ \\
\hline ASA & $\begin{array}{c}r=0.299 \\
p<0.0001\end{array}$ & Hipotansiyon & $\begin{array}{c}\mathrm{r}=0.128 \\
\mathrm{p}<0.0001\end{array}$ \\
\hline Sigara & $\begin{array}{l}\mathrm{r}=0.065 \\
\mathrm{p}=0.041\end{array}$ & Hipertansiyon & $\begin{array}{c}r=0.116 \\
p<0.0001\end{array}$ \\
\hline Alkol & $\begin{array}{l}\mathrm{r}=0.014 \\
\mathrm{p}=0.659\end{array}$ & Bradikardi & $\begin{array}{l}\mathrm{r}=0.076 \\
\mathrm{p}=0.017\end{array}$ \\
\hline DM & $\begin{array}{c}\mathrm{r}=0.142 \\
\mathrm{p}<0.0001\end{array}$ & Taşikardi & $\begin{array}{l}\mathrm{r}=0.102 \\
\mathrm{p}=0.001\end{array}$ \\
\hline HT & $\begin{array}{c}\mathrm{r}=0.154 \\
\mathrm{p}<0.0001\end{array}$ & Desatürasyon & $\begin{array}{c}r=0.276 \\
p<0.0001\end{array}$ \\
\hline КОАН & $\begin{array}{c}\mathrm{r}=0.125 \\
\mathrm{p}<0.0001\end{array}$ & Hipoksemi & $\begin{array}{c}r=0.265 \\
p<0.0001\end{array}$ \\
\hline ASKH & $\begin{array}{c}r=0.208 \\
p<0.0001\end{array}$ & $\begin{array}{l}\text { Postoperatif } \\
\text { transfüzyon }\end{array}$ & $\begin{array}{c}r=0.294 \\
p<0.0001\end{array}$ \\
\hline $\begin{array}{l}\text { İntraoperatif } \\
\text { transfüzyon }\end{array}$ & $\begin{array}{l}1=0.274 \\
p<0.001\end{array}$ & VAS giriş & $\begin{array}{c}r=0.153 \\
p<0.0001\end{array}$ \\
\hline Geç derlenme & $\begin{aligned} \mathrm{r} & =0.149 \\
\mathrm{p} & <0.0001\end{aligned}$ & VAS çıkış & $\begin{array}{c}\mathrm{r}=0.126 \\
\mathrm{p}<0.0001\end{array}$ \\
\hline Anestezi şsekli & $\begin{array}{c}1=0.158 \\
p<0.0001\end{array}$ & Operasyon süresi & $\begin{array}{c}r=0.569 \\
p<0.0001\end{array}$ \\
\hline Ajitasyon & $\begin{array}{l}\mathrm{r}=0.080 \\
\mathrm{p}=0.012\end{array}$ & & \\
\hline
\end{tabular}

Tablo 10. Malignite tanısı olan hastalarda sık görülen komplikasyonlar, n(\%)

\begin{tabular}{|c|c|c|c|c|}
\hline & $\begin{array}{c}\text { Malignite } \\
\text { tanısı } \\
(\mathrm{n}=\mathbf{3 5 6})\end{array}$ & $\begin{array}{l}\begin{array}{c}\text { Malign } \\
\text { olmayan }\end{array} \\
(n=644)\end{array}$ & $\begin{array}{c}\text { Odds oranı } \\
(\% 95 \\
\text { Confidence } \\
\text { interval })\end{array}$ & p \\
\hline Bulantı & $86(\% 24)$ & $57(\% 8,9)$ & $3,2(2,2-4,7)$ & $0,001 *$ \\
\hline Kusma & $7(\% 2)$ & $9(\% 1,4)$ & $1,4(0,5-3,8)$ & 0,494 \\
\hline Aritmi & $10(\% 2,8)$ & $48 \% 0,6)$ & $4,6(1,4-14,8)$ & $0,005^{*}$ \\
\hline Hipoksemi & $15(\% 4,2)$ & $5(\%, 8)$ & $5,6(2,0-15,6)$ & $0,001 *$ \\
\hline Hiperkapni & $8(\% 2,2)$ & $1(\% 0,2)$ & $14,7(1,8-118,6)$ & $0,001 *$ \\
\hline Desatürasyon & $23(\% 6,5)$ & $10(\% 1,6)$ & $4,3(2,0-9,3)$ & 0,001 \\
\hline Hipertansiyon & $55(15,4)$ & $84(\% 13,1)$ & $1,2(0,8-1,7)$ & 0,301 \\
\hline Hipotansiyon & $6(\% 1,7)$ & $26(\% 4,0)$ & $0,4(0,1-1,0)$ & 0,059 \\
\hline Tașikardi & $3(\% 0,8)$ & $9(\% 0,1,4)$ & $0,6(0,1-2,2)$ & 0,443 \\
\hline Bradikardi & $14(\% 3,9)$ & $32(\% 5)$ & $0,7(0,1-1,4)$ & 0,451 \\
\hline
\end{tabular}




\section{REFERANSLAR}

1. Zelcer J, W.D.Anaesthetic related recovery room complications. Anesth Intensive Care 1987; 15: 168-174.

2. Sarah E. Tevis, Gregory D. Kennedy. Postoperative complications and implications on patient-centered outcomes Surg Res 2013; 181(1): 106-113. doi:10.1016/j.jss.2013.01.032.

3. Owens WD, Spitznagel EL. Anesthetic side effects and complications: an overview. Int Anesthesiol Clin 1980; 18: 1-10.

4. Roberta H, P.G., Gail W, et al. Complications Occurring in the Postanesthesia Care Unit: A Surve. Anesth Analg 1992;74: 503-9.

5. Hines R, Barash PG, Watrous G, O'Connor $\mathrm{T}$. Complications occurring in the postanesthesia care unit: a survey. Anesth Analg 1992; 74: 503.

6. Cooper AL, L.J. Tring IC, Admissions to the intensive care unit after complications of anaesthetic techniques over 10 year. Anaesthesia 1989; 44(12): 953-958.

7. Bruins SD, Choo Leong PM, Yi Ng Shin. Retrospective review of critical incidents in the post-anaesthesia care unit at a major tertiary hospital. Singapore Med J 2017; 58(8): 497-501. doi: 10.11622/smedj.2016126

8. Kluger MT, Bullock MF. Recovery room incidents: a review of 419 reports from the Anaesthetic Incident Monitoring Study (AIMS). Anaesthesia 2002; 57: 1060-6.

9. Rose DK, Cohen MM, Wigglesworth DF, DeBoer DP, Math M. Critical respiratory events in the postanesthesia care unit: Patient, surgical, and anesthetic factors. Anesthesiology. 1994; 81: 410 8.

10. Sandner-Kiesling A, L.W. Anesthesia related physiologic and pharmacologic changes in elderly. Anaesthesiol Reanim 2003; 28: 60-68.
11. Wynter Blyth V, Moorthy K. Prehabilitation: preparing patients for surgery. BMJ 2017; 358 doi: https://doi.org/10.1136/bmj.j3702

12. Watcha MF, W.P.Postoperative nausea and vomiting. Its etiology, treatment, and prevention. Anesthesiology 1992; 77: 162-184.

13. Koivuranta M, Laara E, Snare L, Alahuhta S. A survey of postoperative nausea and vomiting. Anaesthesia 1997;52: 443-449.

14. Anderson R, K.K.Pain as a major cause of postoperative nausea. Can Anaesth SOC J 1976; 23: 36-39.

15. Roger Chou, Debra B. Gordon, Oscar A. de LeonCasasola, et al. Guidelines on the Management of Postoperative Pain: A Clinical Practice Guideline From the American Pain Society, the American Society of Regional Anesthesia and Pain Medicine, and the American Society of Anesthesiologists' Committee on Regional Anesthesia, Executive Committee, and Administrative Council. The Journal of Pain, 2016; 17( 2): 131-157.

16. Apfelbaum JL, Chen C, Mehta SS, Gan TJ: Postoperative pain experience: Results from a national survey suggest postoperative pain continues to be undermanaged. Anesth Analg 2003; 97: 534-540.

17. Tong J. Gan, Ashraf S. Habib, Timothy E. Miller, William White and Jeffrey L. Apfelbaum. Incidence, patient satisfaction, and perceptions of post-surgical pain: results from a US national survey. Current Medical Research and Opinion 2014; (30): 149-160.

18. Henrik Kehlet, Troels S Jensen, Clifford J Woolf. Persistent postsurgical pain: risk factors and prevention. 2006; 367: 1618-1625. 